\title{
PROBABILITY OF SPONTANEOUS ABORTION IN MULTIPARAE
}

\author{
D. F. ROBERTS* \\ Department of Human Anatomy, University of Oxford
}

(Received 27th fune 1963)

\begin{abstract}
Summary. Data on abortion incidence in reproductive histories of multiparae are re-analysed to obtain the probability of abortion at a given pregnancy. Division of the data statistically into abortion-prone and abortion-resistant components indicates (a) that there is a greater proportion of the former in the higher pregnancy groups; it is suggested that this may be partly responsible for the apparent increase in abortion incidence with parity and age; (b) that in the abortion-resistant component the probability of abortion at each pregnancy remains constant at about $0 \cdot 12 ;$ (c) that in the abortion-prone component the probability of abortion diminishes from 0.76 in the fourth pregnancy to 0.40 in the ninth. These findings are discussed.
\end{abstract}

\section{GURRENT VIEWS}

As has recently been stressed by Warburton \& Fraser (1961) there is urgent need for reliable estimates of the probability of abortion in the next pregnancy, especially of women who have experienced recurrent abortions, so that they may be helped to decide whether further pregnancy is worth attempting. These authors severely, and justifiably, criticize the calculations made by Malpas (1938) which have been widely quoted, and at times accepted as control figures in studies of preventive therapy, either in their original form or as revised by Eastman (1956). Their criticisms, particularly of the underlying assumptions, are so severe, however, that they give the impression that there are no ways of estimating abortion probabilities from existing data, and that in order to measure these probabilities "the best that can be done is to collect large series of carefully taken reproductive histories ...". While agreeing on the need for further reliable data, this seems an unduly cautious, not to say pessimistic, view and it is perhaps worth reconsidering the points these authors raise.

They reject, it seems with justification, Malpas's (1938) assumption that, after a woman has aborted for a non-recurrent cause, her chances of aborting in a succeeding pregnancy are equal to the frequency of abortion for non-recurrent causes in the population. It is well established that the incidence of spontaneous abortion varies according to the age of the mother. Javert (1957) observed that

* Present address: Department of Anatomy, University of Washington, Seattle, U.S.A. 
in women aged under $20,3.8 \%$ of pregnancies spontaneously aborted, and this percentage steadily increased to $12.6 \%$ in women aged 35 to 39 , and to a higher figure thereafter. Rucker (1952) found percentages of $3.8 \%$ in women aged under 20 years, increasing to $12 \%$ in those aged 35 to 39 years and $18 \%$ in a still older group. Tietze, Guttmacher \& Rubin (1950) found an increase from $4.2 \%$ in females aged under 24 to $11 \%$ in those aged 35 to 39 years. Stanton (1956) noted a higher incidence (32\%) in women 44 years old and over. Stevenson, Dudgeon \& McGlure (1959) observed incidences of $8.7 \%$ in the age group 20 to 24 years, increasing to $25.4 \%$ in the age group 40 to 44 years, though in this series there was a slightly greater incidence in the under20 years group. The incidence of abortions also increases by order of pregnancy until a fairly constant level is reached. Spontaneous abortions in Javert's (1957) series increased regularly from $5.7 \%$ in the first pregnancy to about $18 \%$ in fifth and later pregnancies. Tietze et al. (1950) also noted a rather higher incidence in pregnancies after the first. In the data of Stevenson et al. (1959) the incidence increased from $8.1 \%$ in the first pregnancy to 17 to $19 \%$ in the fifth and later pregnancies. Hudson \& Rucker (1945) recorded an increase from $7.4 \%$ in the first pregnancy, $11.3 \%$ in the second, to yet higher figures thereafter, and in a larger sample Rucker (1952) noted an increase from 5.8\% in women with no previous children to $11 \%$ in those with three. It is, however, not yet clear whether the age and parity effects are independent, though there is some suggestion in the data of Stevenson et al. (1959) that to some extent they may be so. Neither is it clear that such increasing incidence, shown by 'cross-sectional' samples, represents an increasing probability with age or parity in any given individual, to establish which longitudinal study is needed. Such variation, however, does not mean that probabilities of abortion cannot be calculated; it merely means that a probability figure for the population as a whole as envisaged by Malpas (1938) should be replaced by a series of estimates, taking into account the factors with which abortion incidence varies. The data summarized above suggest that there may be a fairly regular progression in the series of estimates for different parities and ages.

A second assumption that Warburton \& Fraser (1961) question is that women who abort for recurrent causes will do so in the first and all succeeding pregnancies. For this assumption, that in a small group of women the abortion probability is unity, existing data show little justification; it was indeed criticized, soon after it was put forward, in an article (A.M.A. Council, 1940) which, while accepting the concept of such a group of recurrent aborters, instead proposed that in them the abortion probability should be rather less than unity but nonetheless still higher than in the remainder of the population. Again, rejection of this assumption does not invalidate the estimation of probabilities; it merely indicates that an unsatisfactory assumption should be replaced by a more likely one, as the A.M.A. Council article advocated.

However, the assumption that is attacked most seriously is that spontaneous abortions occur either for a recurrent cause or for a non-recurrent cause. Warburton \& Fraser (1961) point out that the gestation process must be susceptible to interference by a very large number of agents, and argue by analogy with neonatal mortality that, while some of the situations that cause 
abortion may have a high chance of recurring, and some may have a low chance of recurring, the majority will lie between the two extremes. This argument is to some extent coloured by their succinct discussion (Warburton \& Fraser, 1959) of the role of genes in abortion, in which the same conclusion is implicit. It is worth remembering however (a) that their discussion is essentially in terms of major genes with discrete phenotypic effects, considered individually, whereas, as Dobzhansky (1959) has pointed out, ontogeny does not consist of gradual accretion of autonomous characters, each engendered by a separate gene; instead development is brought about by the genotype, the whole constellation of genes acting in concert, and interacting with the environment. Thus it is possible that conjugation of the gene complex inherited from the father with that from the mother may not lead to normal embryonic development, and there is as yet no means of calculating the probability of this; (b) that direct evidence in man of genetic mechanisms causing abortion is so far limited to incompatibilities at the ABO blood group locus (Matsunaga \& Itoh, 1958), or irregularities in $\mathrm{ABH}$ secretion deriving from the secretor locus (McNeil, Trentelman, Fullmer, Kreutzer \& Orlob, 1957); this is not to say that others do not exist, though there are practical difficulties involved in their detection. Apart from the actuarial approach which they favour to estimate the probability of abortion, the argument of Warburton \& Fraser (1961) implies that the only other solution is the ideal one by which the cause of previous losses would be first identified and then the probability calculated therefrom-the method similar to that employed in genetic counselling centres where advice is sought on the probability of recurrence of a particular deleterious character in further offspring.

\section{ASSESSMENT OF DATA}

\section{THE EMPIRICAL APPROACH}

The problem can instead be approached empirically. There is no doubt that spontaneous abortions do show a tendency to recur in the reproductive history of some women; for instance MacNaughton (1961) recently compared a large sample of second pregnancies, the first one having ended in abortion, with another large sample where the first had ended normally, and showed a higher incidence of threatened abortion and premature labour in the second pregnancies of those previously unsuccessful. However, it is not known whether this tendency is due to persistent factors in the mother's environment, to permanent effects of some temporary environmental factor, or to genetic mechanisms. There is further evidence for this tendency from incidence data. Thus in women with histories of abortion, the incidence was $10.1 \%$ where there had been one previous abortion, and $22.7 \%$ where there had been two or more, by comparison with $6.1 \%$ in those with no previous abortion (Tietze et al., 1950). In Rucker's (1952) sample, the incidence was $5.7 \%$ in women with no previous abortions, $12.8 \%$ in those with one, $17 \%$ in those with two, and $16 \%$ in those with three or more. In Speert's (1954) specialized sample of sixty-six patients with three consecutive previous abortions, the next pregnancy aborted in $11 \%$ of cases, while in fifty-five patients with four or more consecutive previous abortions, $29 \%$ lost the next pregnancy. The histories collected by Warburton \& Fraser 
(1959) showed that by comparison with an abortion incidence of $14.3 \%$ in all pregnancies, the risk of aborting after one previous abortion was $20 \%$, after two was $23 \%$, and after three was $26 \%$.

Further evidence has recently become available, from an analysis by James (1961) of the nature of the distribution curves in Whitehouse's (1930) data on the number of women in each parity group who had experienced a given number of abortions. James (1961) first pointed out that the probability of aborting a pregnancy is not equal in all women in a particular parity group, since the distributions could not be fitted satisfactorily by the expansions of the simple binomial, there being considerable overdispersion. Were there, as envisaged by Warburton \& Fraser (1961), continuous variation in the probabilities of abortion, then the distribution of the data in each parity group might be similar to the expansions of a negative binomial; again, there was poor correspondence with the observed distribution. James (1961) then tested the hypothesis that there were two groups of women in the population, a small group of abortion-prone women, each of whom had a relatively high probability of aborting each pregnancy, and a larger group of abortion-resistant, each with a relatively low probability of aborting each pregnancy; on this hypothesis for each pregnancy group the number of women who had experienced $0,1,2, \ldots n$ abortions would be represented by the terms in the expansion of the double binomial

$$
v_{1}\left(p_{1}+q_{1}\right)^{n}+v_{2}\left(p_{2}+q_{2}\right)^{n}
$$

where $v_{1}$ is the number of abortion-prone women each with a probability of aborting $q_{1}$, and $v_{2}$ is the number of abortion-resistant women, each with a probability of aborting $q_{2}$, and $n$ is the number of previous pregnancies. In this case there was a reasonably good fit between the observed and expected distributions. Admittedly, such curve fitting as a method of analysis has its dangers, particularly when applied to small samples of the size available in each pregnancy group in Whitehouse's series, and when the number of unknowns is, as here, relatively large. None the less, the results are at least suggestive, and James (1961) interpreted them as indicating the existence of two distinct groups of women, one abortion-prone, the other abortion-resistant. He was not particularly interested in the probability values per se, merely indicating that in the histories of the whole sample the probability of aborting for the abortionprone was 0.59 , and for the abortion-resistant was $0 \cdot 11$.

\section{RE-ANALYSIS OF EXISTING DATA}

As pointed out above, more is required than such overall estimates. These should at least be given by pregnancy group, and to be of most use they should be based on data as extensive as possible; for the U.K. there is relatively little available. With the data of Whitehouse (1930) relating to 551 women with three to nine previous pregnancies have been combined those of Stevenson $e t$ al. (1959) for 429 women of the same pregnancy groups. In both sets of data ascertainment was by an abortion, and this index abortion was not included in the histories analysed. There are indeed differences between the samples; the former referred to women in Birmingham, the latter Belfast, a generation apart; 
it has been suggested (e.g. James, 1961) that the former may have included some induced abortions, which Stevenson et al. (1959) maintained are of negligible frequency in the Belfast group. The extent of these differences, however, is not great, as is shown by Table 1 giving the average number of abortions experienced per woman in each pregnancy group relevant to the present analysis, and no great error is involved if these two sets of U.K. data are pooled.

TAble 1

MEAN NUMBER OF ABORTIONS PER WOMAN

\begin{tabular}{c|c|c}
\hline $\begin{array}{c}\text { No. } \\
\text { pregnancies } \\
\text { experienced }\end{array}$ & Belfast & Birmingham \\
\hline 3 & 0.525 & 0.454 \\
4 & 0.676 & 0.618 \\
5 & 0.797 & 0.905 \\
6 & 0.978 & 1.070 \\
7 & 1.102 & 1.394 \\
8 & 1.308 & 1.514 \\
9 & 1.500 & 1.333 \\
\hline
\end{tabular}

TABLE 2

PROBABILITIES OF ABORTION FROM HISTORIES

\begin{tabular}{|c|c|c|c|c|c|}
\hline \multirow{2}{*}{$\underset{\substack{\text { No. } \\
\text { previous } \\
\text { pregnancies }}}{ }$} & \multirow[b]{2}{*}{ No. subjects } & \multicolumn{3}{|c|}{ Probability of abortion from histories in } & \multirow{2}{*}{$\begin{array}{c}\% \text { of sample } \\
\text { abortion- } \\
\text { prone }\end{array}$} \\
\hline & & $\begin{array}{l}\text { Total } \\
\text { sample }\end{array}$ & $\begin{array}{c}\text { Abortion- } \\
\text { prone } \\
\text { component }\end{array}$ & $\begin{array}{c}\text { Abortion- } \\
\text { resistant } \\
\text { component }\end{array}$ & \\
\hline $\begin{array}{l}3 \\
4 \\
5 \\
6 \\
7 \\
8 \\
9\end{array}$ & $\begin{array}{r}290 \\
244 \\
164 \\
102 \\
82 \\
63 \\
35\end{array}$ & $\begin{array}{l}0.161 \\
0.161 \\
0.172 \\
0.172 \\
0.174 \\
0.179 \\
0.156\end{array}$ & $\begin{array}{l}0.828 \\
0.707 \\
0.624 \\
0.486 \\
0.527 \\
0.381 \\
0.411\end{array}$ & $\begin{array}{l}0.134 \\
0.113 \\
0.136 \\
0.111 \\
0.120 \\
0.112 \\
0.117\end{array}$ & $\begin{array}{r}3 \cdot 85 \\
8 \cdot 02 \\
7 \cdot 34 \\
16 \cdot 06 \\
13 \cdot 25 \\
24 \cdot 70 \\
13 \cdot 24\end{array}$ \\
\hline
\end{tabular}

Using the pooled data, the probabilities from the histories have been calculated, for each pregnancy group separately, as a whole and distinguishing the abortion-prone and abortion-resistant components (Table 2; Text-figs. 1 and 2). The findings are indeed surprising. The probability of abortion in the abortionprone component shows a clear tendency to diminish the higher the pregnancy group. No such marked trend is apparent in the probability of abortion in the abortion-resistant component, which appears to remain remarkably constant over the parity range examined. Thirdly, the proportion of abortion-prone to the total number in each successive parity group tends to rise. These estimates are particularly sensitive to slight variations in the distribution in each pregnancy group, and the values are of course subject to sampling error-the same trends are shown, but are rather less regular, in the Birmingham data analysed alone-but, considering the small sample size in the higher pregnancy groups even in the pooled data, the trends are remarkably clear. They suggest that 
something more than chance is responsible for the statistical distinction of the two components.

The apparently greater proportions of abortion-prone in higher pregnancy groups, it may be suggested, indicate attempts at compensation for earlier losses by those women who have been more severely affected; whatever the

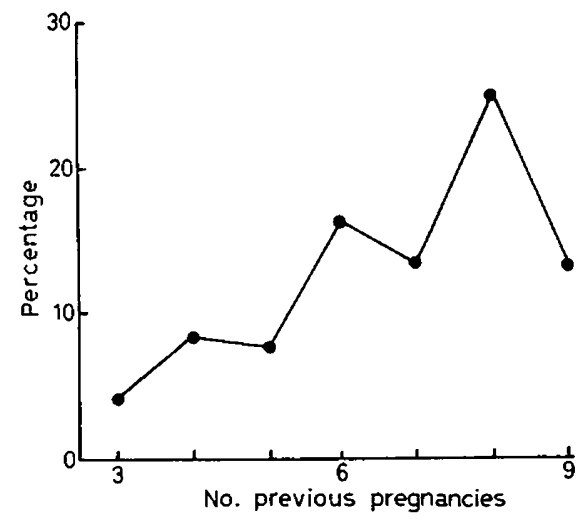

TeXT-Fig. 1. Percentage of abortion-prone women in each pregnancy group (pooled data).

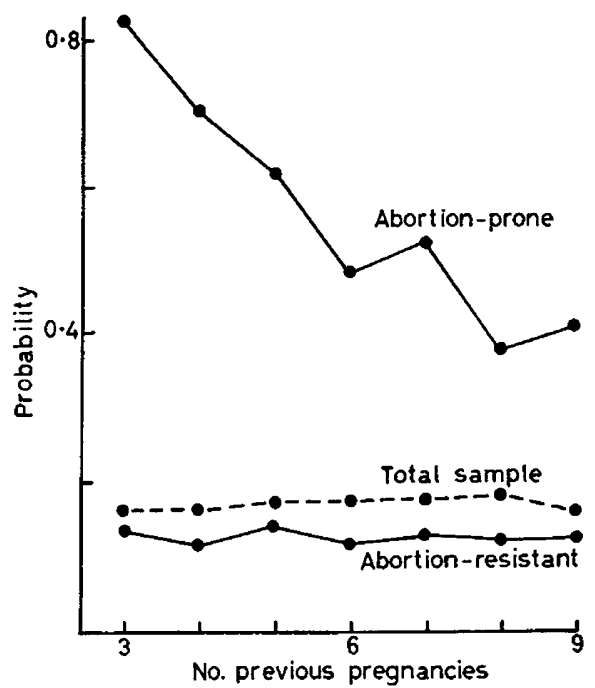

Text-rig. 2. Probability of abortion by number of previous pregnancies (pooled data).

cause, however, this finding could well account at least in part for the increasing abortion incidence with parity noted in so many studies. As for the probability findings in each component, these, it must be emphasized, do not refer to the outcome of the third or the fourth or any particular pregnancy; they are the probabilities shown by the past reproductive histories of successive groups of women on the assumption that the probability remained constant at all previous pregnancies in each group, but not from group to group. In the case of the resistant component there is no difficulty; a constant probability of abortion at each pregnancy, to be expected if all such losses were due to chance 
causes, of the order of about $0 \cdot 121$ would result in the generally level graph shown in Text-fig. 2. For the abortion-prone component, on the other hand, the observed diminution is compatible with the above assumption if only the more favoured among these experiencing a given pregnancy proceed to the next; alternatively it may perhaps suggest that the assumption is not valid; for instance, women who had aborted more than once may have tended to take increasing care in later pregnancies. However, this difficulty scarcely impedes the calculation of the probability of loss at a given pregnancy, which is performed as follows.

TABLE 3

SMOOTHED VALUES USED IN THE GALCULATION OF PROBABILITIES OF LOSS AT A GIVEN PREGNANCY

\begin{tabular}{c|c|c}
\hline $\begin{array}{c}\text { No. previous } \\
\text { pregnancies }\end{array}$ & $\begin{array}{c}\text { Mean No. } \\
\text { abortions per } \\
\text { woman per } \\
\text { pregnancy }\end{array}$ & $\begin{array}{c}\text { \% of sample } \\
\text { abortion-prone }\end{array}$ \\
\hline 3 & 0.165 & 5.12 \\
4 & 0.166 & 7.53 \\
5 & 0.167 & 9.94 \\
6 & 0.168 & 12.35 \\
7 & 0.168 & 14.76 \\
8 & 0.169 & 17.17 \\
9 & 0.170 & 19.58 \\
\hline
\end{tabular}

TABLE 4

PROBABILITY OF SPONTANEOUS ABORTION AT A GIVEN PREGNANCY

\begin{tabular}{|c|c|c|}
\hline \multirow[b]{2}{*}{$\begin{array}{c}\text { Pregnancy } \\
\text { (1) }\end{array}$} & \multicolumn{2}{|c|}{ Probability of loss at each pregnancy } \\
\hline & $\begin{array}{c}\text { In abortion-prone } \\
\text { component } \\
(2)\end{array}$ & $\begin{array}{l}\text { In total } \\
\text { (3) }\end{array}$ \\
\hline $\begin{array}{l}\text { 4th } \\
5 \text { th } \\
\text { 6th } \\
7 \text { th } \\
8 \text { th } \\
9 \text { th }\end{array}$ & $\begin{array}{l}0.756 \\
0.618 \\
0.533 \\
0.476 \\
0.435 \\
0.404\end{array}$ & $\begin{array}{l}0.168 \\
0.170 \\
0.172 \\
0.173 \\
0.175 \\
0.176\end{array}$ \\
\hline
\end{tabular}

To overcome sampling error a smooth regression line is fitted relating the average number of abortions per woman per pregnancy experienced (i.e. the probability of abortion) in the total sample to the number of previous pregnancies (Table 3). It is a simple matter then to calculate the loss at each successive pregnancy necessary to produce the observed change in these smoothed averages, the values being shown in Table 4 and Text-fig. 3 ; this procedure assumes that women who proceed say to the sixth pregnancy are representative of all those who experience fifth pregnancies. Then, from the smoothed values (Table 3 ) for the proportion of each component in each pregnancy group and 
from the constant probability of loss for the abortion-resistant, is calculated the loss at each pregnancy in the abortion-prone required to produce that observed in the total sample. Thus for women experiencing a fifth pregnancy, the $90.1 \%$ in the resistant category with an abortion probability of 0.12 are responsible for 109 abortions in every 1000 pregnancies; however, at the fifth pregnancy the expected number of abortions is 170 , and the difference must be due to the $9.9 \%$ of women in this group who are abortion-prone, in whom then the probability of abortion must be $0 \cdot 618$. The probabilities at each pregnancy thus
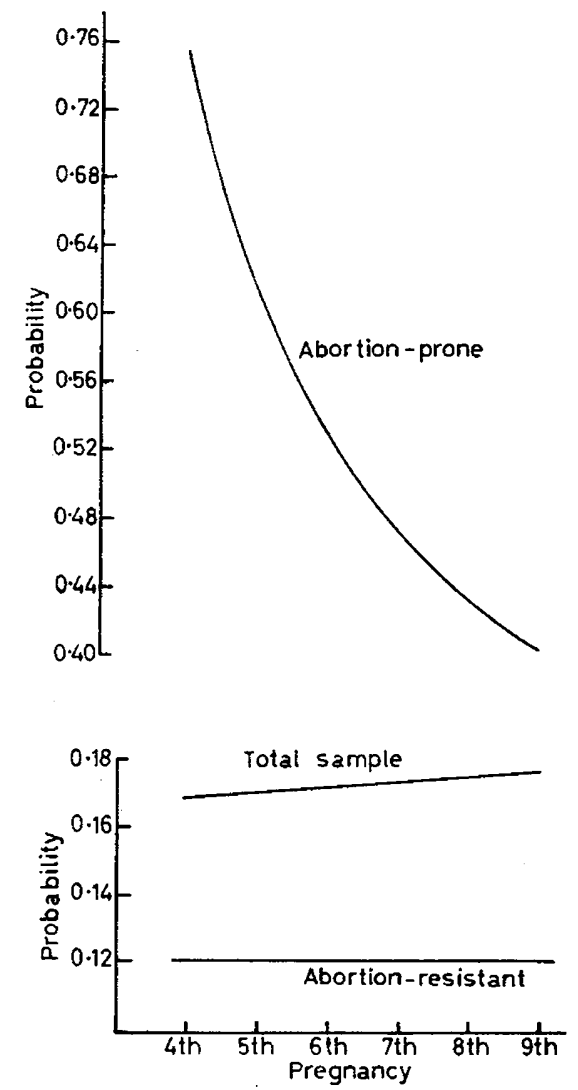

TEXT-FIG. 3. Probability of spontaneous abortion at a given pregnancy.

calculated indirectly for the abortion-prone are set out in column 2 of Table 4 and in Text-fig. 3. These figures are fairly close to the probabilities observed for the abortion-prone in the histories, which seems to suggest that it is indeed the constitution of this component that is changing. Should it be objected that the small number of women who had experienced nine pregnancies may be unduly influencing the shape of the smoothed regression, the calculations omitting this group gave very similar results.

These are to be regarded as little more than intriguing speculations and are only offered as such in the hope that others may be able to examine their clinical validity. Further statistical confirmation is of course required of the 
distinction of two components and of the probabilities calculated, for some quirk in the collection of the data, affecting say the probability of loss in the total sample or the proportions of the two components present, would have a serious effect on the estimates of loss at a given pregnancy. But most important is the need for biological confirmation of the distinction of two components, and there remains, when this is done, the problem of the criteria to use in assigning an individual to one or other of the categories-a problem which has not arisen in the present study where the distinction has been between two groups, and has been made purely statistically. In the meanwhile, since they may be of interest in group comparisons, the probabilities of abortion at a given pregnancy are offered, their drawbacks notwithstanding, in the absence of any more satisfactory estimates. If one is unconvinced by the statistical distinction of the two components, then the probabilities to be used are those for the total sample (Table 4, column 3); if, however, one is interested in the abortion-resistant group, the probability of loss seems to be unchanged from pregnancy to pregnancy at about $0 \cdot 121$; while if one is primarily concerned with recurrent aborters, then the estimates to use are those in Table 4, column 2. But whichever estimates are used, advice to anxious multigravidae contemplating further pregnancy should perhaps be more encouraging than was formerly thought.

\section{REFERENCES}

A.M.A. Council (1940) The treatment of habitual abortion with vitamin E. American Medical Association Council on Pharmacy and Chemistry. F. Amer. Med. Ass. 114, 2214.

Dobzhansky, T. (1959) On selection of gene systems in natural populations. Natural Selection in Human Populations, p. 49. Ed. D. F. Roberts and G. A. Harrison. Pergamon Press, Oxford.

Eastman, N. J. (1956) William's Obstetrics, 11 th edn. Appleton, Century Crofts, New York.

Hudson, G. S. \& RuCker, M. P. (1945) Spontaneous abortion. 7. Amer. med. Ass. 129, 542.

JAMEs, W. H. (1961) On the possibility of segregation in the propensity to spontaneous abortion in the human female. Ann. hum. Genet. 25, 207.

JAVERT, C. T. (1957) Spontaneous and habitual abortion. McGraw-Hill, New York.

MacNaughton, M. C. (1961) Pregnancy following abortion. 7. Obstet. Gynaec. Brit. Cwilth. 68, 789.

Malpas, P. (1938) A study of abortion sequences. F. Obstet. Gynaec. Brit. Cwlth. 45, 932.

Matsunaga, E. \& Iтон, S. (1958) Blood groups and fertility in a Japanese population with special reference to intra-uterine selection due to maternal-foetal incompatibility. Ann. hum. Genet. 22, 111 .

McNeil, G., Trentelman, E. F., Fullmer, C. D., Kreutzner, V. O. \& Orlob, R. B. (1957) The significance of blood group conflicts and aberrant salivary secretion in spontaneous abortion. Amer. J. clin. Path. 28, 469.

Rucker, M. P. (1952) Spontaneous abortions; too many or too few? 7. int. Coll. Surg. 17, 328.

Speert, H. (1954) Pregnancy prognosis following repeated abortion. Amer. J. Obstet. Gynec. 68, 665.

Stanton, E. F. (1956) Pregnancy after 44. Amer. 7. Obstet. Gynec. 71, 270.

Stevenson, A. C., Dudgeon, M. Y. \& McGlure, H. I. (1959) Observations on the results of pregnancies of women resident in Belfast. II. Abortions, hydatiform moles and ectopic pregnancies. Ann. hum. Genet. 23, 395.

Tietze, C., GutTmacher, A. F. \& Rubin, S. (1950) Unintentional abortion in 1497 planned pregnancies. 7. Amer. med. Ass. 142, 1348.

Warburton, D. \& Fraser, F. C. (1959) Genetic aspects of abortion. Clin. Obstet. Gynec. 2, 22.

Warburton, D. \& Fraser, F. G. (1961) On the probability that a woman who has had a spontaneous abortion will abort in subsequent pregnancies. F. Obstet. Gynec. Brit. Cwlth. 68, 784.

Whrtehouse, B. (1930) Discussion on the causes of early abortion and sterility. Proc. roy. Soc. Med. 23, 248. 